Website: https://e-journal.iainsalatiga.ac.id/index.php/islah

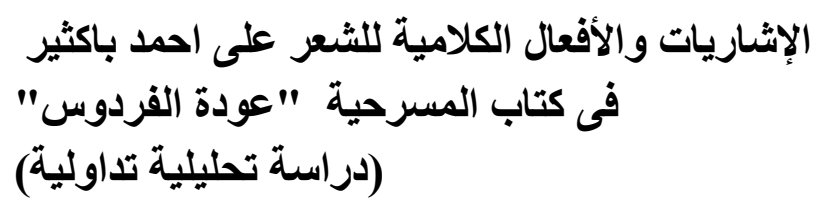

\title{
Deixis and Speech Acts of a Poem by Ali Ahmad Bakatsir on Drama Script Entitled "Audatul Firdaus"
}

\author{
Maftuh Ahmad ${ }^{1}$, Rina Susanti ${ }^{2}$ \\ ${ }^{1}$ Pondok Pesantren MTs-MA NU Assalam Kudus, ${ }^{2}$ IAIN Salatiga \\ ahmedatuh0@gmail.com, rinasusantiiainsalatiga.ac.id
}

\begin{abstract}
This article aims to describe the type of deixis and speech acts, as pragmatics studies aspects, found in a poem by Ali Ahmad Bakatsir, an Indonesian-born poet, on drama script entitled "Audatul Firdaus". Audatul Bakatsir tells about Indonesian Independence which was as the result of Indonesian people's fight not as the colonialists' gift. This research is a library research with qualitative method. The results shows that there are five types of deixis and six types of speech acts. The former one consists of persona, space, time, discourse, and social. Moreover, the later one include locutionary, perlocutionary, illocutionary, assertive, expressive, and commissive.
\end{abstract}

Key words: Deixis, Pragmatics, Speech Acts

\begin{abstract}
Abstrak
Artikel ini bertujuan untuk mendeskripsikan bentuk-bentuk deiksis dan tindak tutur sebagai aspek kajian pragmatik pada puisi di buku drama "Audatul Firdaus" karya Ali Ahmad Bakatsir seorang penyair kelahiran Indonesia. Audatul Firdaus berbicara tentang kemerdekaan bangsa Indonesia yang merupakan hasil perjuangan rakyatnya, bukan hadiah dari penjajah. Penelitian ini merupakan penelitian kepustakaan (library research) dengan metode kualitatif. Hasil penelitian menunjukkan bahwa ditemukan 5 bentuk deiksis dan 6 bentuk tindak tutur. Bentuk deiksis yang dimaksud, terdiri dari: 1) persona, 2) ruang, 3) waktu, 4) wacana, dan 5) social. Sedangkan bentuk tindak tutur yang 6 yakni:lokusi, ilokusi perlokusi, asertif, ekspresif, dan komisif.
\end{abstract}

Kata kunci : Deiksis, Pragmatik, Tindak Tutur 
Deixis and Speech Acts of a Poem by Ali Ahmad Bakatsir...(Maftuh Ahmad \& Rina Susanti)

في كتاب علم اللغة، يقول أيتشيسون (Aitchison) أن اللغويات لها تتضدن الصوتيات

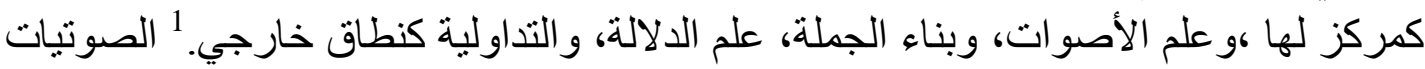

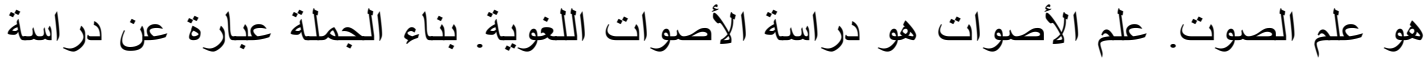

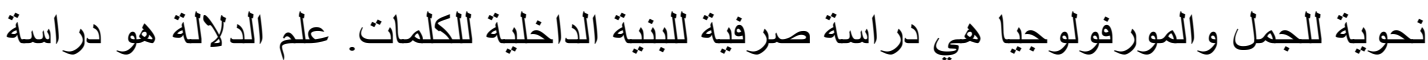

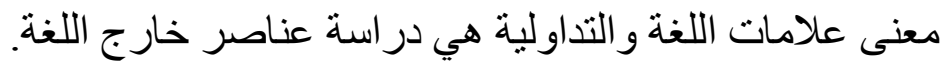

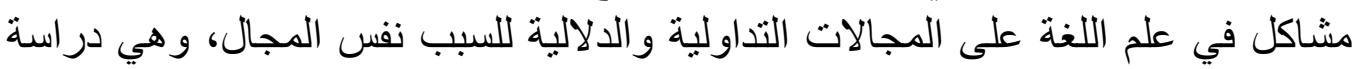

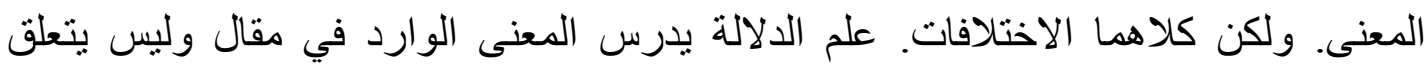
بالسياق، والتداولية يدرس المعنى فى خارج اللغة فيما يتعلق بمعرفة الخلفية بين المتحدث

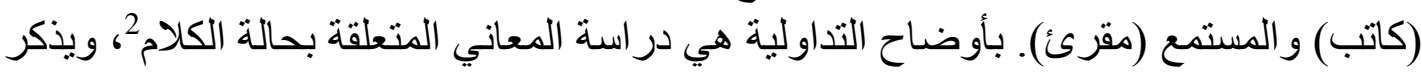
جان أيتشيسون: (ك)

"Pragmatic is the branch of linguistics which studies those aspects of meaning which cannot be captured by semantic theory. In brief, it deals with how speakers use language in ways which cannot be predicted from linguistic knowledge alone. In a narrow sense, it deals with how listeners arrive at the intended meaning of speakers. In its broadest sense, it deals with the general principles followed by human beings when they communicate with one another".

يترجم مصطلح (Pragmatics) بعدة كلمات باللغة العربية، فهنالك : الذرائعية،

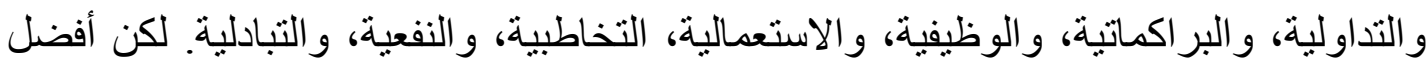

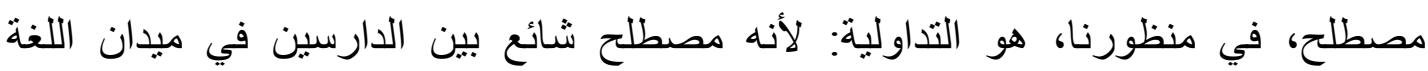

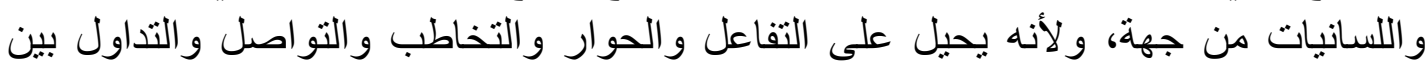
الأطر اف المتلفظة من جهة أخرى.

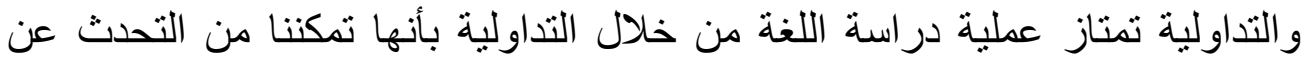

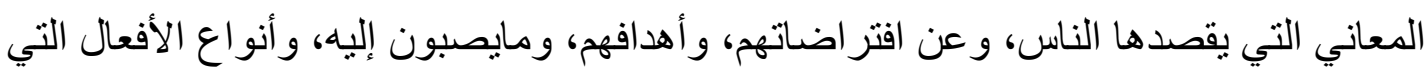

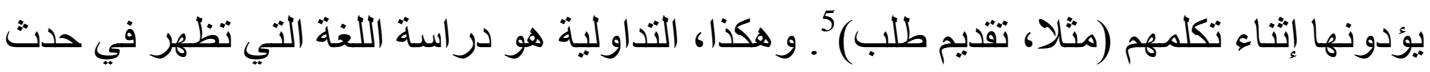

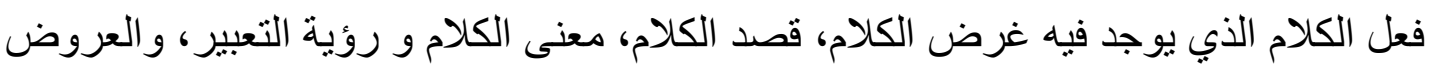

\footnotetext{
${ }^{1}$ Aitchiso, Jean, Linguistics (15th ed.) (London: Hodder and Stoughton, 1999), 7-10.

${ }^{2}$ Leech, Geoffrey, Principles of Pragmatics (10 ${ }^{\text {th }}$ ed.) (New York : Longman Group Limited, 1996), 13.

${ }^{3}$ Aitchiso, Op. cit, 93.

$$
\text { 5 جميل حمداوي، التداوليات وتحليل الخطاب، حقوق الطبع محفوظة للمؤلف، بدون مكان، 2015، ص: } 5 .
$$
}




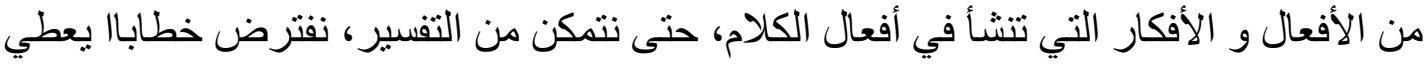
في النهاية الآثر في التو اصل موسائل التو اصل الاجتماعي التي لها تأثير كبير في حياة الإنسان.

يول (Yule) في كتابه "التداولية"ا6 يتحدث أن أعمال الكلام هي محاولة للتعبير عن أنفسهم،

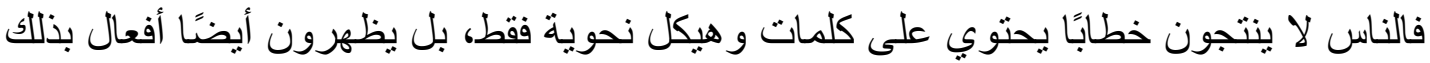

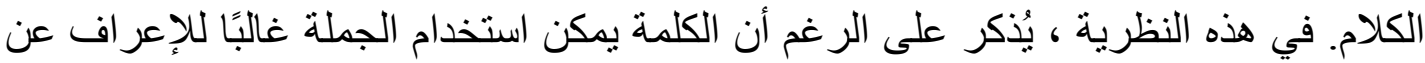

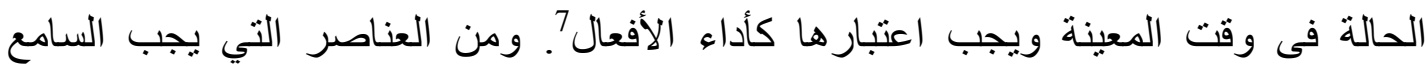
لتفهيمها يعنى: الإشاريات و و الأفعال الكلامية.

إن الإثاريات هي الكلمات التي تثبر إلى أو تحدّد فردا معينا أو مكانا معينا من بين

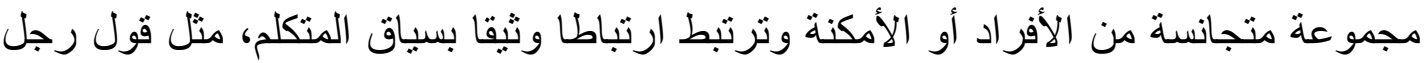

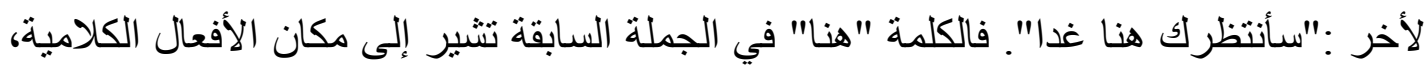

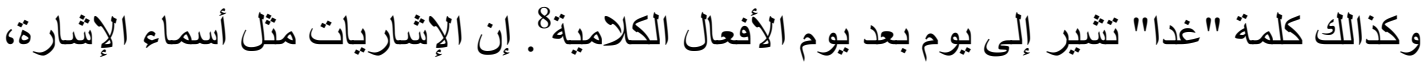

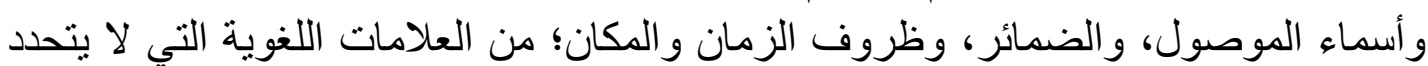

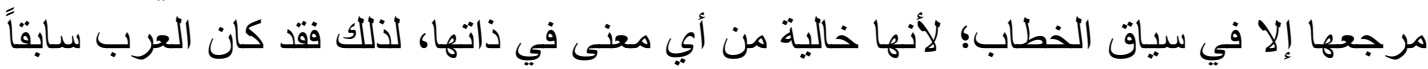

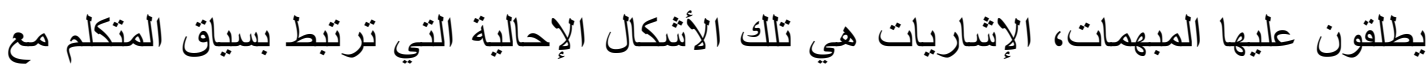
التفريق الأساس بين التعبيرات الإثارية القريبة من المتكلم مقابل التعبيرات الإنشارية الإنية البعيدة

هنا خمس انواع الإشاريات وهي الإشاريات الثخصية (Deiksis persona) و الإشاريات

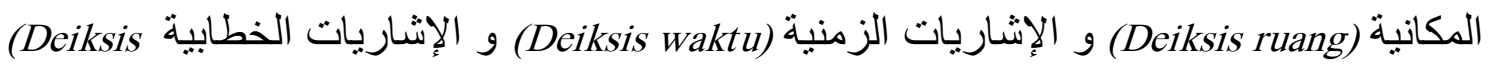

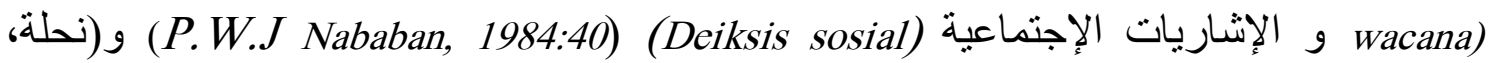
محمود احمد، 17)، التى سيبحثها فيما يلى الإتئية (10:

$$
\text { أ. الإثاريات الثخصية (Deiksis persona) }
$$

وهي تثنمل ضمائر المتكلم، والغائب، و المخاطب. فذالك الضمائر عناصر إنشارية، لأن مرجعها يعتمد إعتمادا تاما على السياق الذى تستخدم فيه111.

مثل : (1) أنا نعسان. فالسياق هو الذي يحدد إحالة الضمير (أنا).

$$
\text { ب. بالإشاريات المكانية) (Deiksis ruang) }
$$

\footnotetext{
${ }^{6}$ Yule, George,The Study of Language ( $3^{\text {rd }}$ ed) (New York: Cambridge University Press), 81

${ }^{7}$ Jinani, Hurul, Fenomena Tindak Tutur dalam Surat Al-Ghasyiyyah: Suatu Tinjauan Pragmatik. Makalah. (Malang: Jurusan Sastra Arab, Fakultas Sastra Universitas Negeri Malang, 2012).

${ }^{8}$ Kushartanti, et.el, Pesona Bahasa: Langkah Awal Memahami Linguistik (Jakarta : PT. Gramedia 2007), 111.

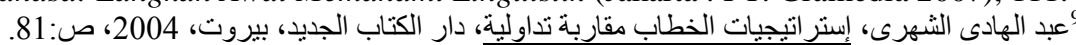

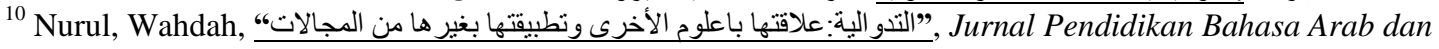
Kebahasaan, vol 4, No. 1, (2016): 43-45. 
Deixis and Speech Acts of a Poem by Ali Ahmad Bakatsir...(Maftuh Ahmad \& Rina Susanti)

وهي كلمات الإشارة نحو هذا وذاك للإنشارة إلى قريب أو بعيد من مركز

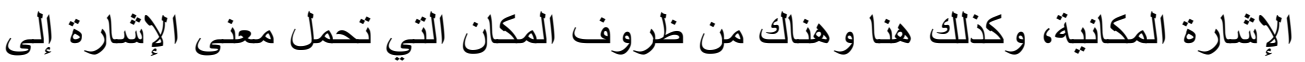

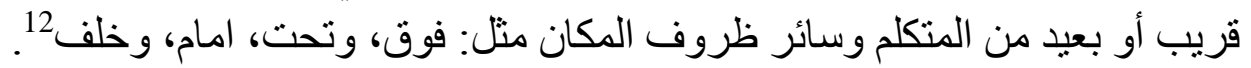

$$
\text { ت. الإشاريات الزمنية) Deiksis waktu) }
$$

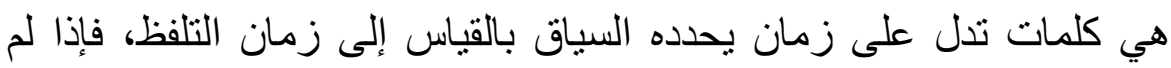

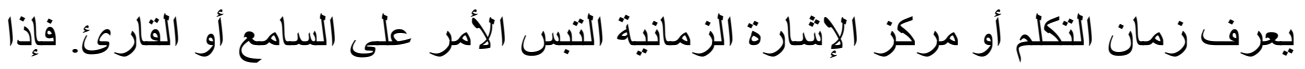

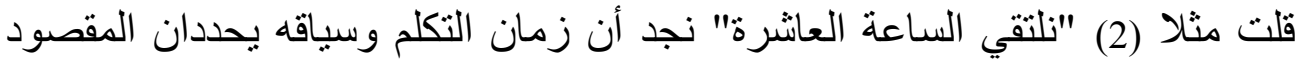

$$
\text { بالساعة العاشرة صباحا أم مساء اليوم أو غدا. }
$$

$$
\text { ث. (Deiksis wacana) (الإشاريات الخطابية) }
$$

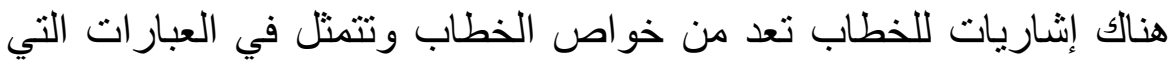

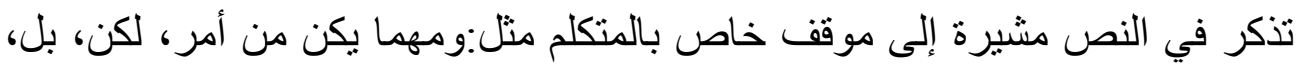

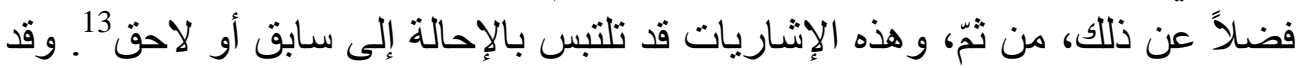

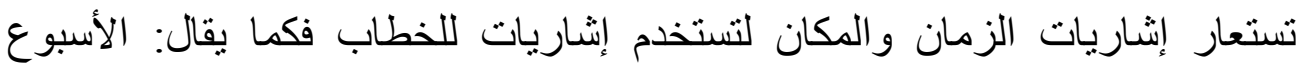

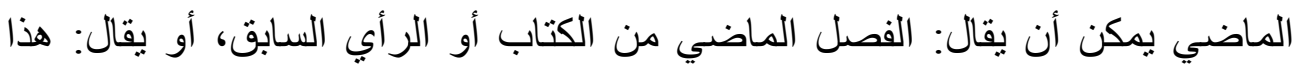

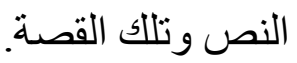

$$
\text { ج. الإشاريات الاجتماعية (Deiksis Sosial) }
$$

وهي ألفاظ وتراكيب تنثير إلى نوع العلاقة الإجتماعية بين المتكلمين

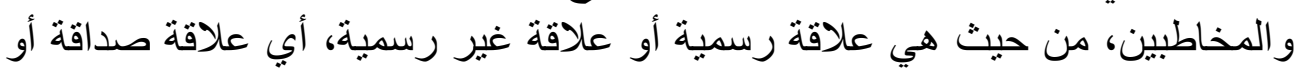

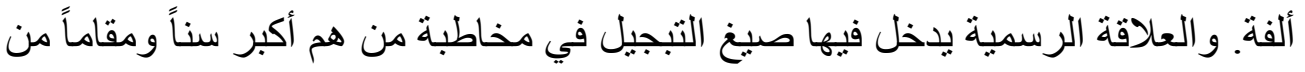

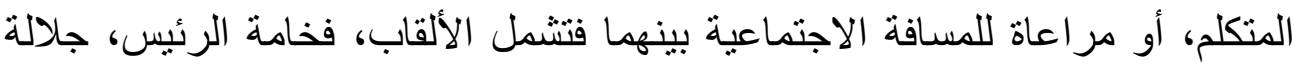

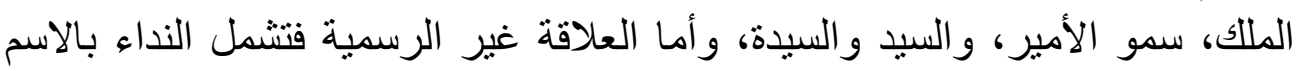

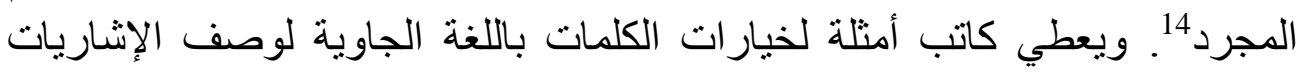

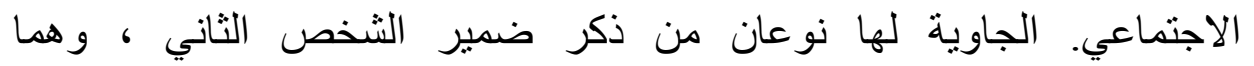

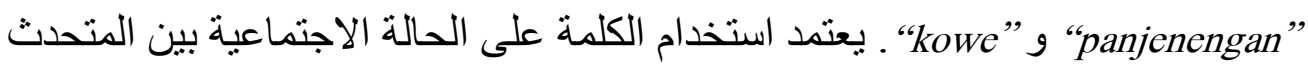

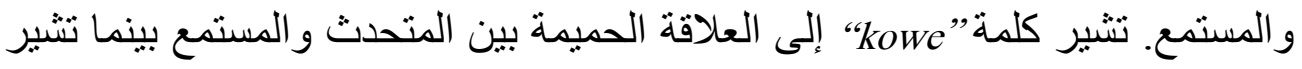

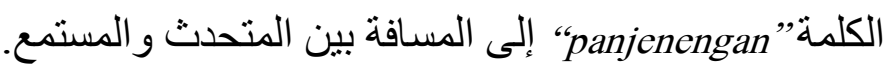

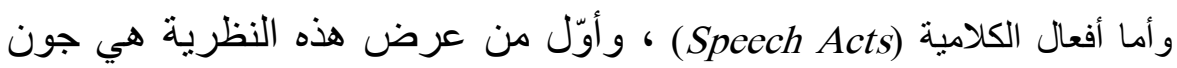

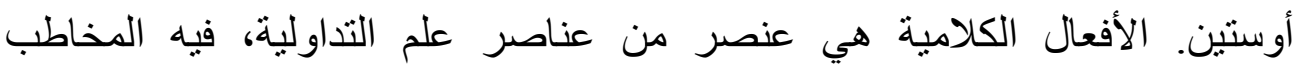

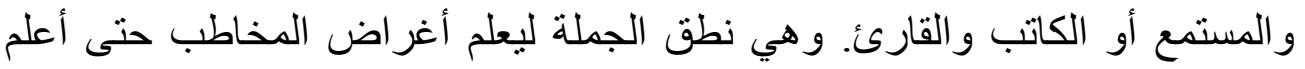

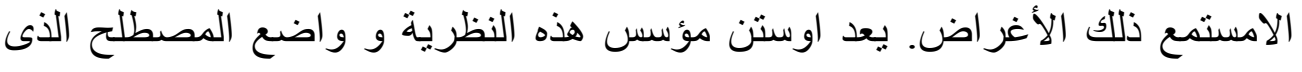




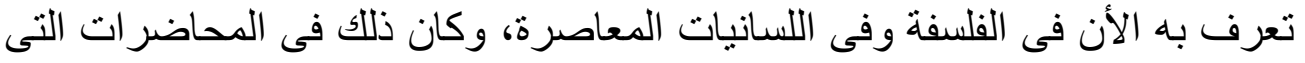

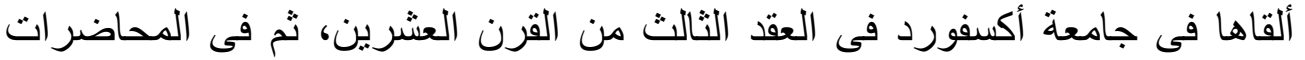

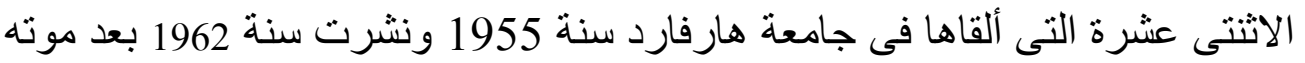

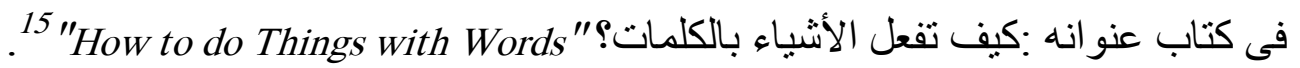

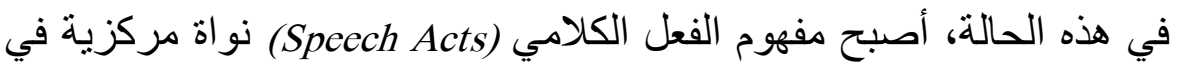

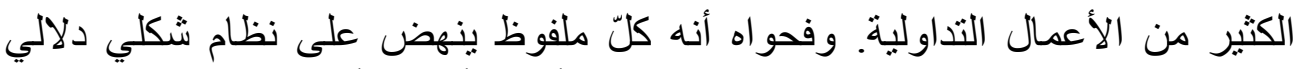

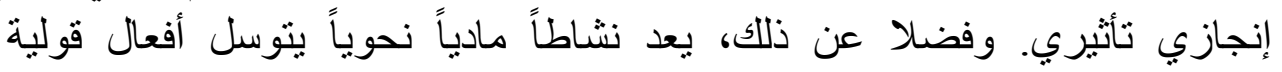

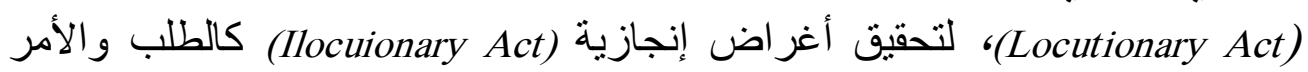

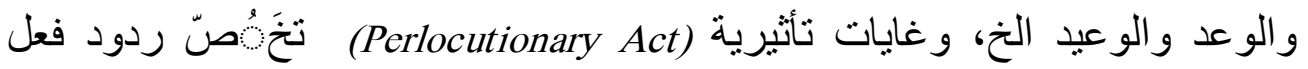
المتلقي(كالر فض و القبول)

$$
\text { أ. أفعال القولية (Locutionary Act) }
$$

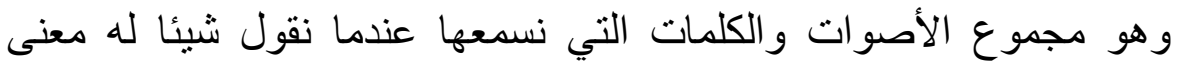

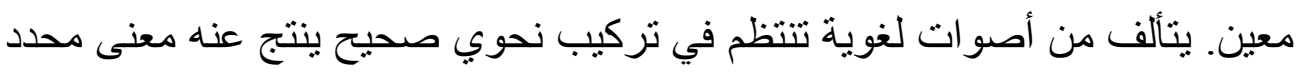
و هو المعنى الأصلي، ولو مرجع يحيل إليه. انظر في المثنال الثنالي. (3) أغلق ذاك

في الجملة (3)، الجملة "أغلق ذاك الباب" هي تعبير عن الفعل القول.

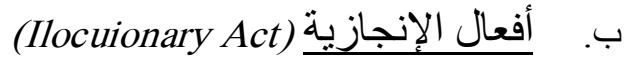

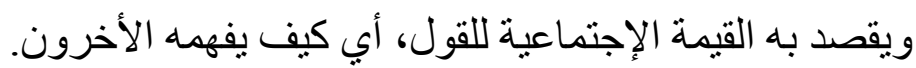

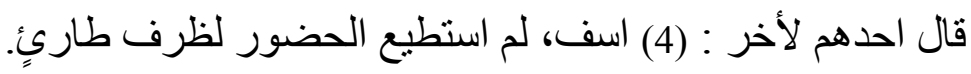

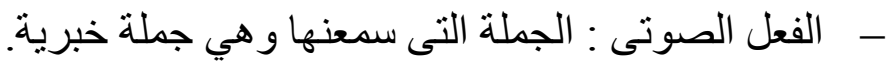

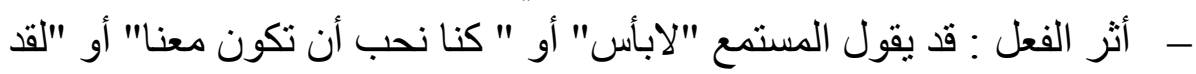

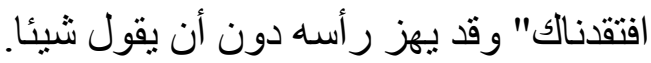
- - الفعل المقصود : الإعنذار.

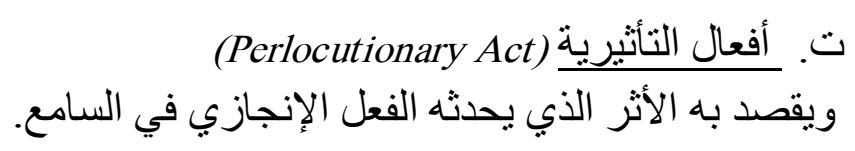
مثال: (5) "الدكان بعيد". وقد قدم سيرل "Searle" تصنيفاً للأفعال الكلامية على أساس أفعالها الإنجازية

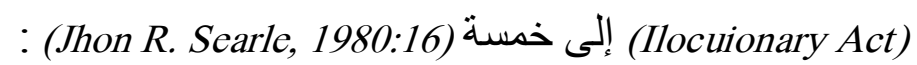
1

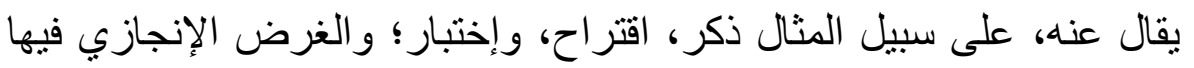

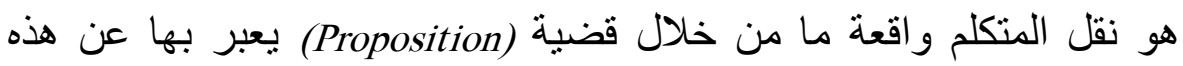
الو اقعة. و أفعال هذا الصنف كلها تستمل لصدق و الكذب. و واتجاه كلمات فيها من عن هن 
Deixis and Speech Acts of a Poem by Ali Ahmad Bakatsir...(Maftuh Ahmad \& Rina Susanti)

الكلمات إلى العالم ويتضم هذا الصنف من أفعال معظم أفعال الأيضاح'17.

$$
\text { وتقوم على الإعلان عن حكم تأسس على البداهة. }
$$

(6) مثل: إخلاء الذمة، واعتباره كالو عد.

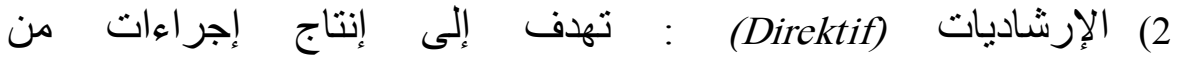

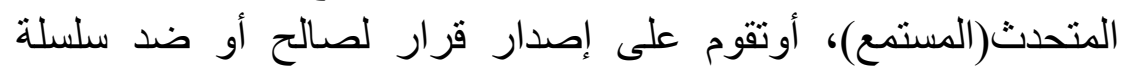

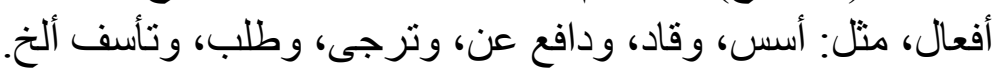

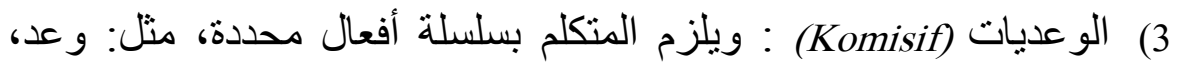

$$
\text { وتمنى، و التزم بعقد، و أقسم إلخ. : التخ }
$$

4) التعبير ات (Ekspresif) : يتعلق الأمر بردود فعل اتجاه سلوك الآخر ، مثل:

الاعتذار ، الثكر،التهنئة.

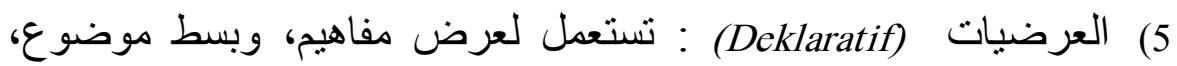

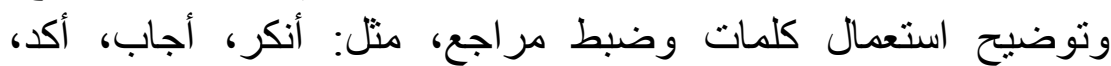

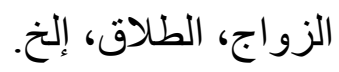

إعتمادا على البحث السابق، سيناقش الباحث اللغة المكتوبة حول أفعال الكلام و الإشاريات في

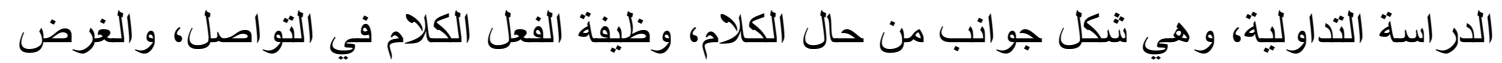

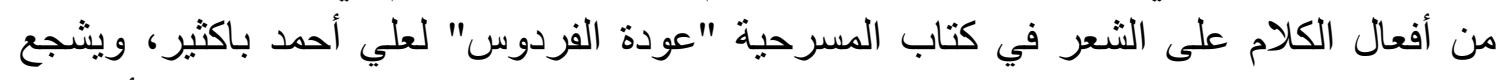
الباحث على إجر اء بحث في مجال التداولية مع مجموعة من البيانات الثعرية و الباحث يأخذ هذه مجموعة بيانات شعرية بالشعر في كتاب المسرحية "عودة الفردوس" لعلي أحمد باكثير الموجودة

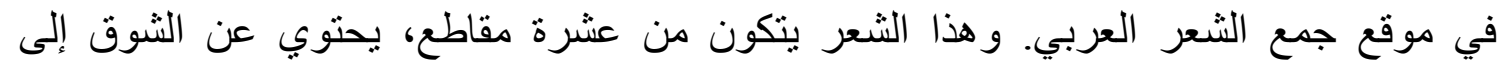

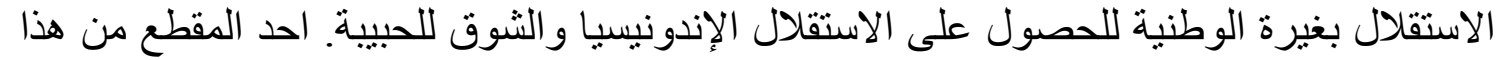

الشعر كما يلي:

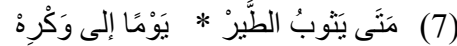

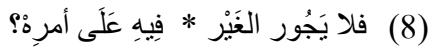

إذا ذللك المثال (7) و (8) من جانب الدلالة فإن ما يحدث سيكون جملة توضحية فقط. ولكن

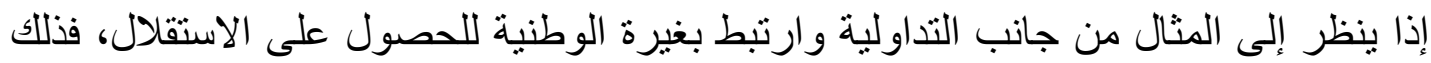

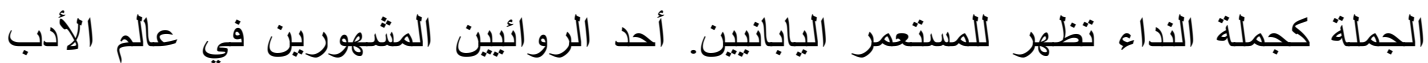
العربي هو علي أحمد باكثر. وهو روائي وشاعر وكاتب درامي مشهور من إندونيسيا. وكثير

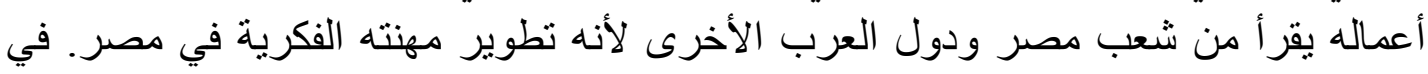
عالم تاريخ الأدب العربي، ثم تعيينه كأديب حديث، وهو نفي نفس الجيل من الأديب المصريين المشهورين منه نجيب محفوظ، و عزيز أباظة، ويحيى حقي، ود. عبده بدوي، و و عدد من الأديب الآخرين. يُعرف بأنه أول أديب يكتب دراما باللغة العربية الفصحى ورائدا في الدراما ودادي

الفلسطينية.

بناء على تعرض الخلفية السابقة ليكون هذا البحث بحثاو اضحا، تحدد المسألة كما يلى :

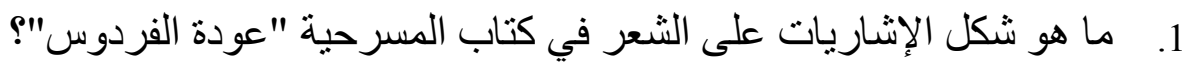

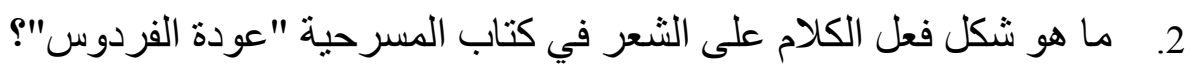




\section{منهج البحث}

هذه المادية عبارة عن الثعر في كتاب المسرحية "عودة الفردوس" لعلي أحمد باكثير

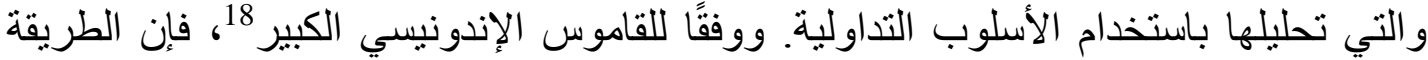
هي طريقة منظمة تستخدم التففذ الوظيفة لكى وفقا لأساليب العمل المر غوبة أو المنهجية لتسهيل

$$
\begin{aligned}
& \text { تنفيذ نشاط حتى لتحقيق } \\
& \text { الأهداف المحددة. لتحني. } \\
& \text { أ. . طريقة حصول البيانات }
\end{aligned}
$$

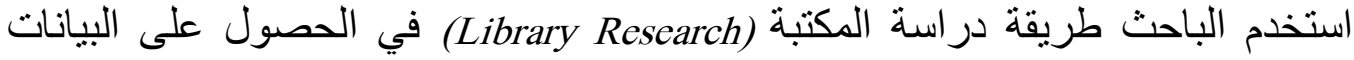

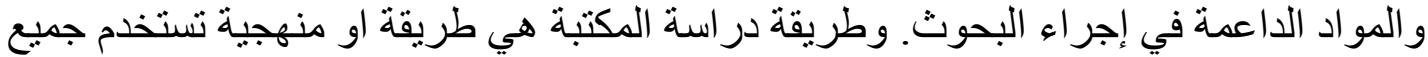

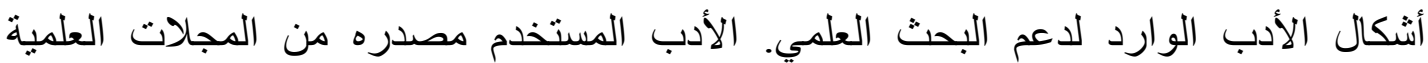
و الأطروحات و التسبس و الكتب الددرسية و الوسائط الإلكترونية.

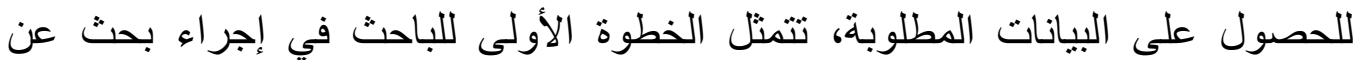

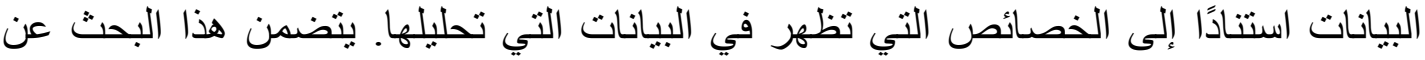
أفعال الكلام و الإشاريات للشعر في كتاب المسرحية "عودة الفردوس" لعلي الكيات أحدد باكثير.

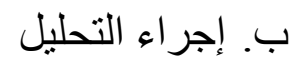

إجراء التحليل الذي يفعل الباحث بعد الحصول على البيانات، فيما يلي:

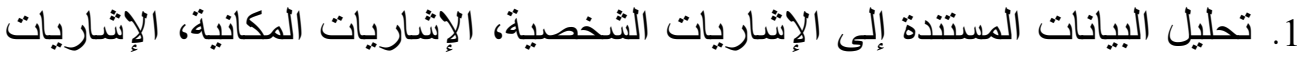

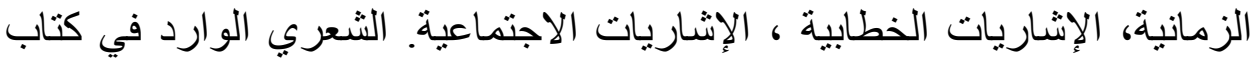

$$
\text { المسرحية "عودة الفردوس" لعلي أحمد باكثير. }
$$

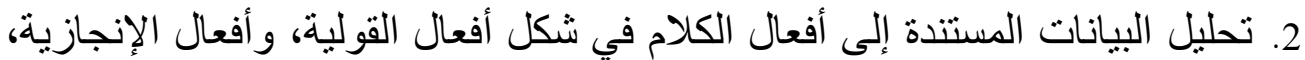

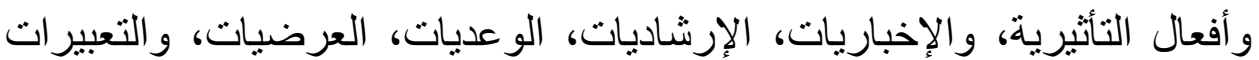

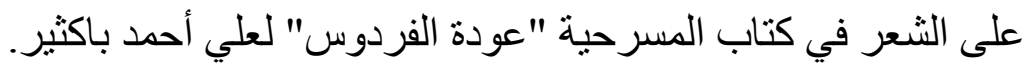
3. إجر اء فرضية حتى يحصل الباحث على إجابة من صياغة المشكلة.

\section{أ. لمحة عن الكتاب المسرحية عودة الفردوس}

من بين الأعمال الأدبية لباكثير ، أكثر من ثلاثثين أعمال أدبية المسرحية. الموضوع

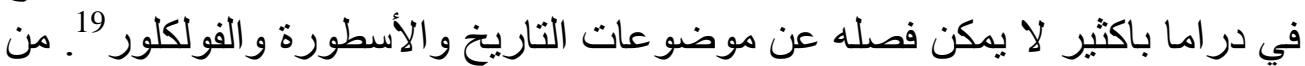

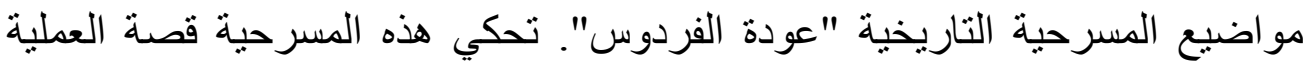
التاريخية لنضال إندونيسيا من أجل الاستقلال.

\footnotetext{
${ }^{18} \mathrm{Apk}, K B B I V 02.1$ Beta (21)

${ }^{19}$ Starkey, Paul. "Modern Arabic Literature". Edinburg: Edinburg University Press Ltd, 2006, 186.
} 
Deixis and Speech Acts of a Poem by Ali Ahmad Bakatsir...(Maftuh Ahmad \& Rina Susanti)

بسماحة المسرحية، باكثير يحاول أن يؤكد أن استقلال الشعب الإندونيسي كان

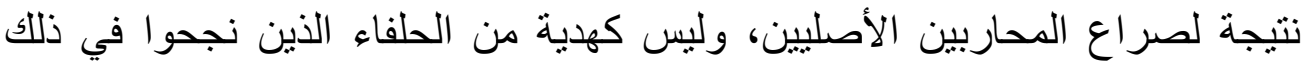
الوقت في مستعمر اليابان من إندونيسيا.

لعبت "عودة الفردوس" على ثلاثة عشر ممثلاً. اما الممثلون الثلاثة عثر منهم

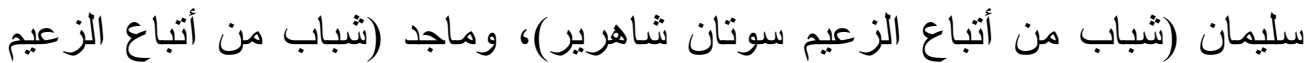

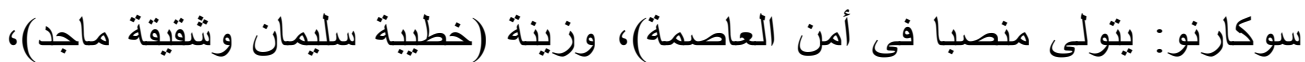

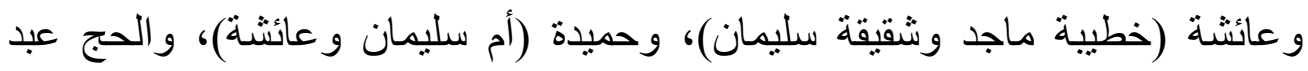

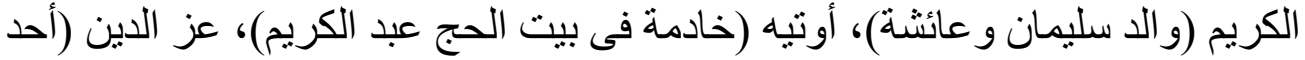

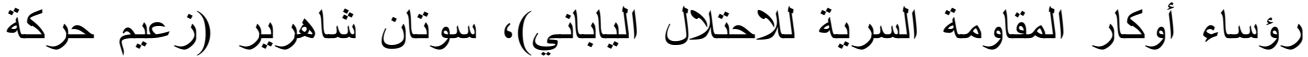

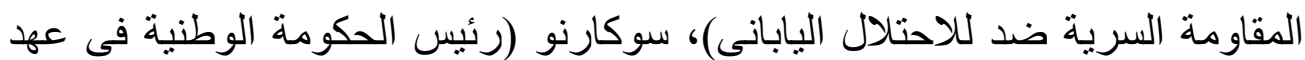

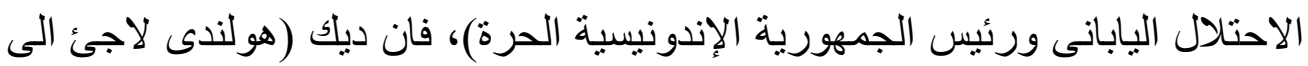

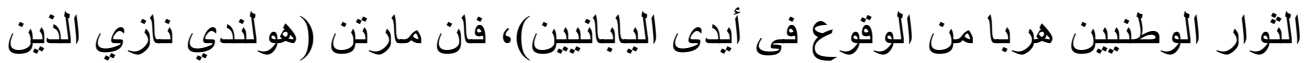

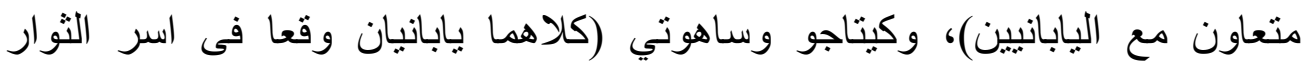
الوطنيين)، والجنود أو الحر اس.

ويعرض الممثلين المسرحية من خلال حوارات المسرحية بأربع فصول. يبدأ

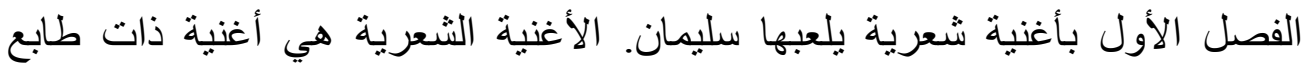

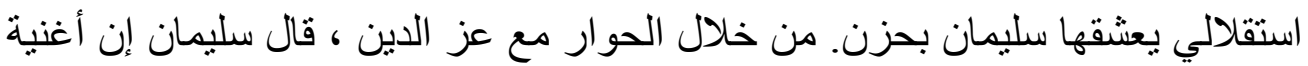
الحزن تنشأ بسبب الفقر والمعاناة التي يعاني منها الإندونيسيون. ثم استُقبلت الأغنانية بأغنية أجابها عز الدين الذي حاول تشجيع سليمان على أن الاستقلال سيأتي قريبًا. قال

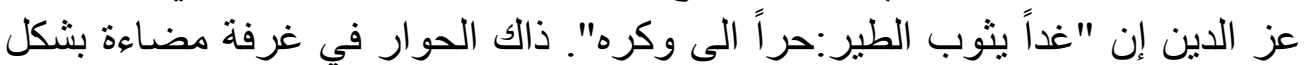

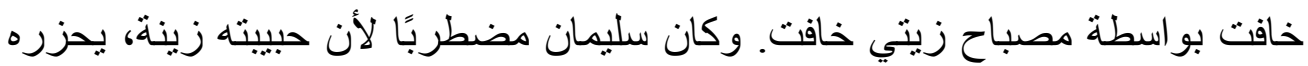

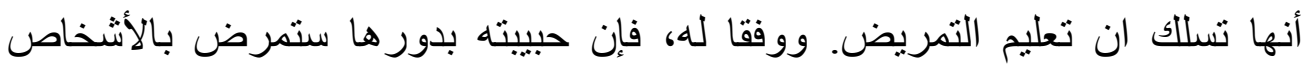
و الجنود اليابانيين الذين يعتبرون في كثير من الأحيان غير أخلاقيين للممرضات فئه السكان الأصليين.

الفصل الثاني يقع في منزل الحاج عبد الكريم حو الي الساعة الخامسة بعد العصر. في هذا الفصل كان هنالك حوار بين عبد الكريم، حميدة، عائشة، اوتيه، ماجد، وسليمان. جرى حوار طويل بين مجيد وسليمان اللذين كانا يتجادلان حول القومية بيد بين أنباع أنباع

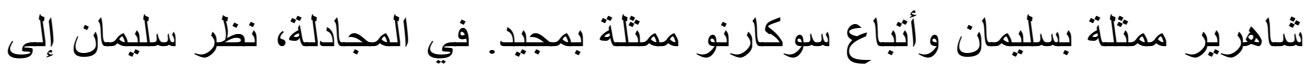

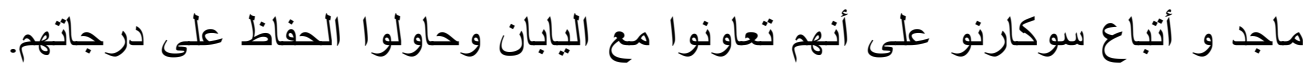

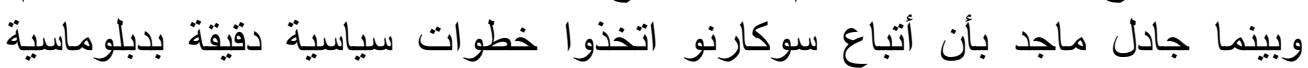
الاستقلال التي انحرفت وقللت ضحايا الحرب الجسدية ضد اليابان.

في حين أن مجموعة شاهرير يعتبر مجيد بالمخاطر لأنها تضحي بحياة المدنيين

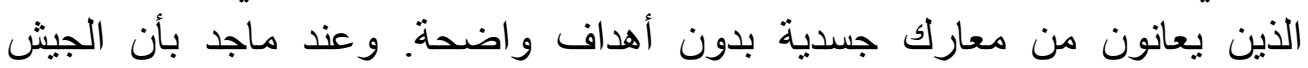

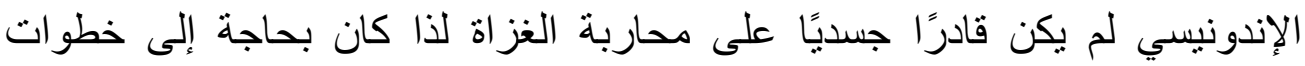


دبلوماسية لتحقيق الاستقلال. وبينما لايزال سليمان على تحارب لأجل الاستقلال بالحرب المادية (الجسدية).

يبدأ الفصل الثالث بأغنية الثعرية على سليمان حول شوق الاستقلال الإندونيسي.

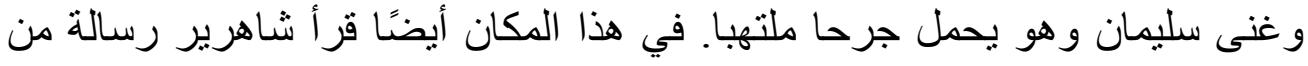

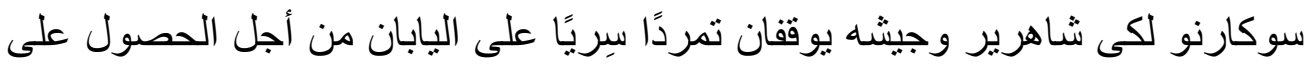

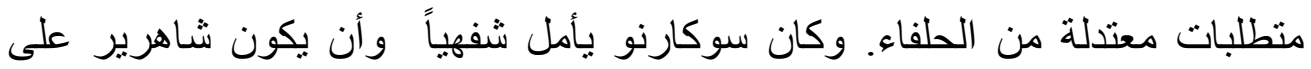
استعداد لأن يصبح رئيسًا للاولة.

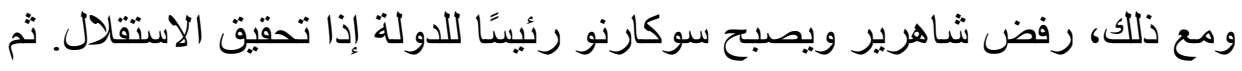

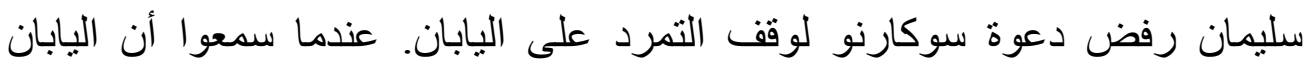

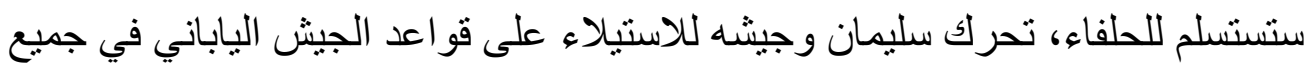

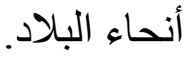

الفصل الرابع يحكي الأحداث التي وقعت في 17 أغسطس 1945 في منزل عبد إنداب

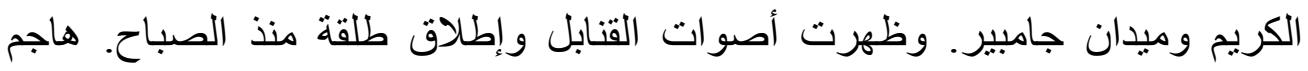

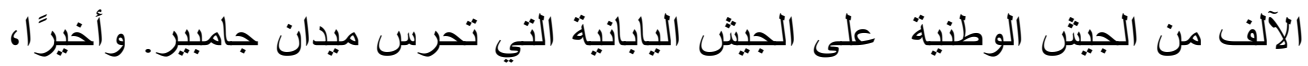

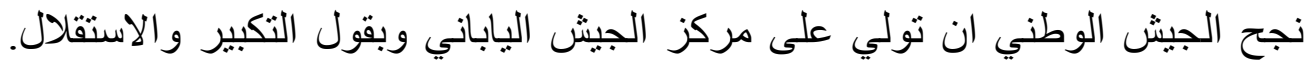

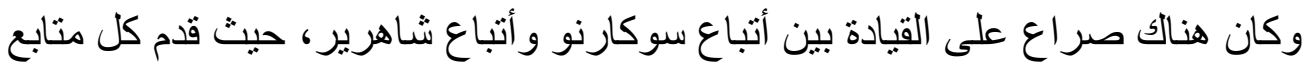
قادته.

وبعد أن ألقى كل من سوكارنو وشاهرير الخطب وطرحوا زملائهم (اقترح سوكارنو على شاهرير و العكس) ، ثم اختيار سوكارنو كرئيس للبلاد

ب. عرض البيانات وتحليلها ومناقشتها عن الإشاريات وأفعال الكلامية

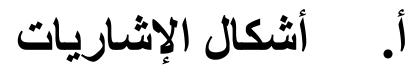

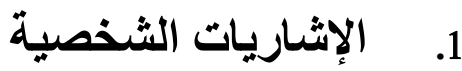

وجد الباحث الإنشاريات الثخصية في شعر ، منها كما يلي:

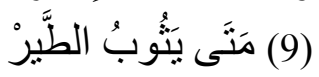

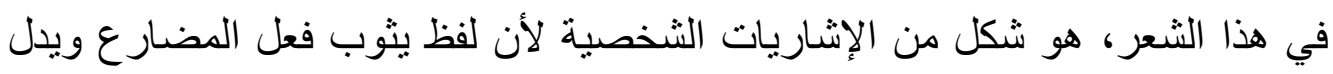

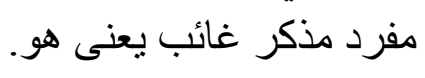

(10) فلا يَجُور الغَيْرْ

في هذا الثعر، هو شكل من الإثـاريات الثخصية لأن لفظ يجور فعل المضار ع ويدل

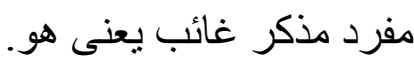

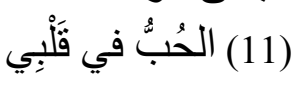

في هذا الثُعر، هو شكل من الإشاريات الثخصية لأن لفظ قلبي ضمير متصل بياء متكلم.

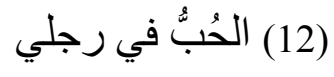

في هذا الثعر، هو شكل من الإشاريات الثخصية لأن لفظ رجلي ضمير متصل بياء 
Deixis and Speech Acts of a Poem by Ali Ahmad Bakatsir...(Maftuh Ahmad \& Rina Susanti)

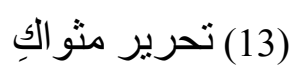

في هذا الشعر، هو شكل من الإشـاريات الشخصية لأن لفظ مثوالكِ ضمير متصل بمعنى مؤنث مخاطب.

\section{2. الإثاريات المكاتية}

و هي كلمات الإشارة نحو هذا وذاك للإشتارة إلى قريب أو بعيد من مركز

الإشارة المكانية، وكذللك هنا و هنالك من ظروف هوف المكان التي تحمل معنى الإشارة

إلى قريب أو بعيد من المتكلم وسائر ظروف المكان مثل: فوق، وتحت، وهن امام، وخلف

(نحلة، 2002، 22).

وجد الباحث الإشاريات المكانية في شعر، منها كما يلي:

$$
\text { (14) }
$$

في هذا الشعر، هو شكل من الإشاريات المكانية لأن لفظ إلى وَكُرْه يدل

$$
\text { الإشارة المكانية.ّ. }
$$

في هذا الثعر، هو شكل من الإشاريات المكانية لأن لفظ في الأكُبَاذْ يدل

\section{3. الإثاريات الزماتية}

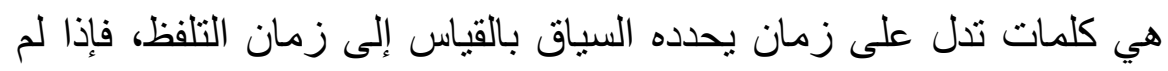

يعرف زمان التكلم أو مركز الإشارة الزمانية التبس الأمر على التى السامع أو القارئ. وجد الباحث الإشاريات الزمانية في شعر ، منها كما يلي:

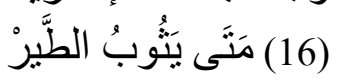

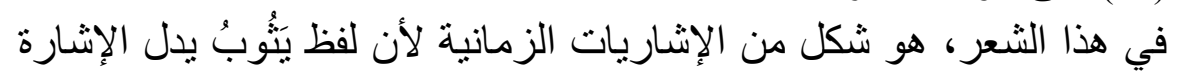

الزمانية بالقياس إلى زمان التلفظ بمعنى حاضر او الأنى الأن.

$$
\text { غدا يَتُُبُ الطَّبرْ }
$$

في هذا الشعر، هو شكل من الإشاريات الزمانية لأن لفظ غدا يدل الإشارة الزمانية.

\section{4. الإثاريات الاجتماعية}

هي ألفاظ وتراكيب تثنير إلى نوع العلاقة الإجتماعية بين المتكلمين و المخاطبين، من حيث هي علاقة رسمية أو علاقة غير رسمية، أي علاقة صداقة الاقية أو ألفة.

$$
\text { وجد الباحث الإشَاريات الإجتمائية في شَعر، كما يلي: }
$$


في هذا الثعر، هو شكل من الإشاريات الإجتماعية لأن ما العلاقة بين المتكلم و المخاطب، من حيث هي علاقة غير رسمية.

\section{ب. أشكال أفعال الكلامية

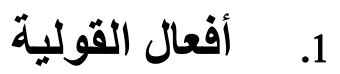

هو مجموع الأصو ات و الكلمات التي نسمعها عندما نقول شيئًا له معنى معين.

$$
\begin{aligned}
& \text { وجد الباحث أفعال القولية في الشعر، منها كما يلي: } \\
& \text { (19) مَتَى يَتُوبُ الطَّبرْز * يَوْمًا إلىى وَكْرِه: } \\
& \text { (20) فلا يَجُور الغَيْرْ * فِيهِهِ عَلَى أمرِهْ }
\end{aligned}
$$

في هذا الثعر، وهو شكل من الأفعال القولية لأنه فيها البيان، أن سليمان

$$
\text { يعطى البيان إلى المستعمرين. }
$$

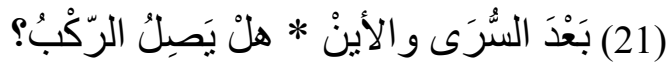

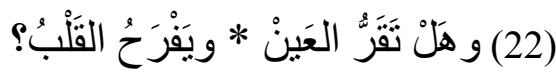

في هذا الثعر، و هو شكل من الأفعال القولية لأنه فيها البيان، أن سليمان

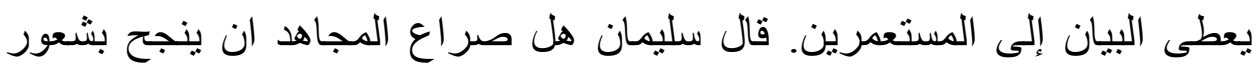

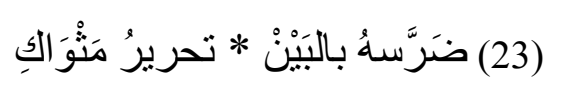

في هذا الثعر، وهو شكل من الأفعال القولية لأنه فيها البيان، أن سليمان النيان

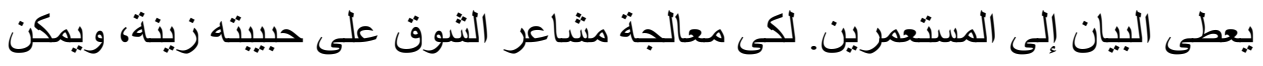
استقلال وطنه على الفور الفئن الفعرين

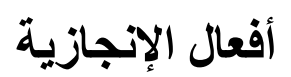

هو يقصد به القيمة الإجتماعية للقول، أي كيف يفهمه الأخرون.

$$
\begin{aligned}
& \text { وجد الباحث أفعال الإنجازية في الثعر ، كما يلي: } \\
& \text { (24) مَتَى يَتُوبُ الطَّيْرْ * يَوْمًا إلىى وَكْرِه: }
\end{aligned}
$$


Deixis and Speech Acts of a Poem by Ali Ahmad Bakatsir...(Maftuh Ahmad \& Rina Susanti)

$$
\text { (25) فلا يَجُور الغَبْرْ * فِيهِه عَلَى أمرِْْ }
$$

في هذا الشعر، وهو شكل من فعل الكلام الإخبارية. هذا الكلام من أفعال

$$
\text { الإنجازية. }
$$

\section{3. أفعال التأثيرية}

$$
\begin{aligned}
& \text { هو يقصد به الأثر الذي يحدثه الفعل الإنجازي في السامع. } \\
& \text { وجد الباحث أفعال الإنجازية في الثعر ، كما يلي: } \\
& \text { (26) فلا يَجُور الغَيْرْ * فِيهِه عَلَى أمرِهْ } \\
& \text { (27) } \\
& \text { (28) زَيْنُ اذْكُرِي يازَيْنْ * هَيمانُ يَهْوَالَِ } \\
& \text { (29) ضَرَّسهُ بالبَيَنُْْ * تحريرُ مَنْوَ الكِ }
\end{aligned}
$$

بعد أن بحث وحلل الباحث من أشكال الإشاريات والأفعال الكلامية في هذا البحث تحت

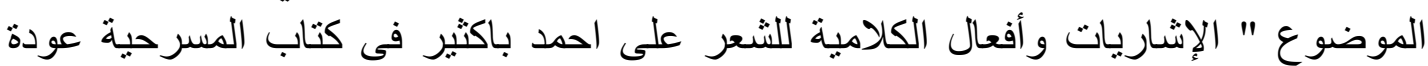
الفردوس"، فالنتيجة من هذا البحث كما يلي:

1. أثكال الإشاريات فى الثعر على احمد باكثير فى كتاب المسرحية عودة

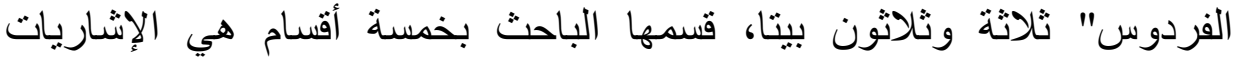

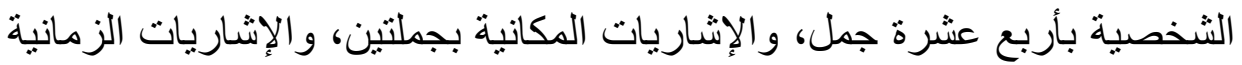
بإحدى عشرة جمل، والإشاريات الخطابية بخمسة جمل، و الإشاريات الإجتماعية بجملة و احدة.

2. أثكال الأفعال الكلامية فى الثعر على احمد باكثير فى كتاب المسرحية عودة الفردوس" أربعة وعشرون بيتا، قسمها الباحث بثلاث أقسام هي الأفعال كلامية اللفظية بعثرة جمل، والأفعال كلامية الإنجازية يتكون من فعل فيده الكلام الإخبارية

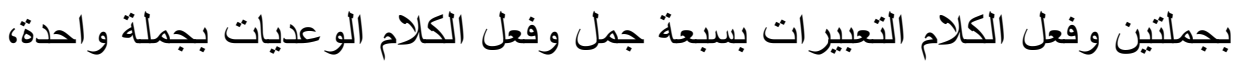
و الأفعال كلامية التأثيرية بأربعة جمل التعل.

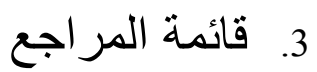

\section{المراجع العربية}

باكثير، على احمد. عودة الفردوس. القاهرة، مكتبة مصر ، بدون تاريخ. 


$$
\begin{aligned}
& \text { حمداوي، جميل. التداوليات وتحليل الخطاب. حقوق الطبع محفوظة للمؤلف، } 2015 \text { م. } 2015 \text { م. }
\end{aligned}
$$

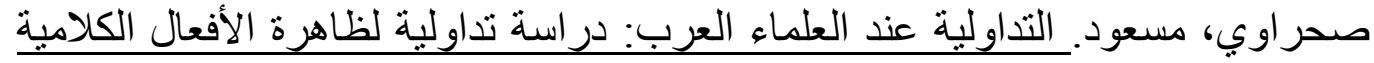

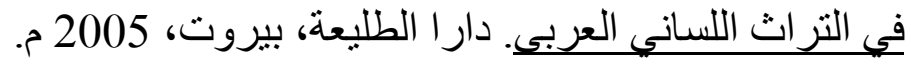

$$
\begin{aligned}
& \text { على، محمد يونس. مقدمة في علمي الدلالة والتخاطب. دار الكتاب الجديد المتحدة، }
\end{aligned}
$$

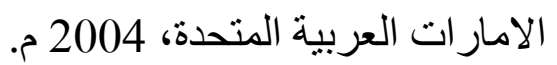$$
\text { المتوكل، أحمد. دراسات في نحو اللغة العربية الوظيفي. الدر البيضاء: دار الثقافة } 1986
$$$$
\text { نخلة، محمود أحمد. أفاق جديدة في البحث اللغوي المعاصر. دار المعرفة، الأسكندارية، }
$$$$
2000
$$$$
\text { يول، جورج .التداولية، بناية الريم :الدار العربية للعلوم ناشرون ش.م.ل 2010م. }
$$$$
\text { أ. المراجع الأجنبية }
$$

\section{REFERENCE}

Aitchiso, Jean. Linguistics (15th ed.). London: Hodder and Stoughton, 1999.

Apk, KBBIV 02.1 Beta (21)

Cahyono, Bambang Yudi. Kristal-Kristal Ilmu Bahasa. Surabaya: Airlangga University Press, 1995.

Grundy, Peter. Doing Pragmatics. London: Hooder Headline PLC, 1995.

Gunarwan, Asim. Analisis Klausa, Pragmatik Wacana, Pengkomputeran Bahasa.

Pertemuan Linguistik Lembaga Bahasa Atma Jaya: 7, 83- 89. Jakarta: Lembaga Bahasa Inika Atma Jaya, 1994.

Jinani, Hurul. Fenomena Tindak Tutur dalam Surat Al-Ghasyiyyah: Suatu Tinjauan Pragmatik. Makalah. Malang: Jurusan Sastra Arab, Fakultas Sastra Universitas Negeri Malang, 2012.

Kridalaksana, Harimurti. Bahasa dan Linguistik, Jakarta: PT Gramedia Pustaka Utama, 2005.

Kushartanti. Pragmatik, Jakarta: PT Gramedia Pustaka Utama, 2005.

Leech, Geoffrey. Principles of Pragmatics (10th ed.). New York: Longman Group Limited, 1996.

Levinson, Stephen. Pragmatics. London. Cambridge, Massachusetts: Blacwell Publishers, 1983.

Mey, Jacob L. Pragmatics An Introduction. Cambridge, Massachusetts: Blackwell Publishers, 1993. 
Deixis and Speech Acts of a Poem by Ali Ahmad Bakatsir...(Maftuh Ahmad \& Rina Susanti)

Rokib, Muhammad. Kembalinya surga firdaus: menilik kemerdekaan Indonesia melalui pandangan 'Ali Ahmad Bākathīr dalam drama 'Audat Al-firdaus, Jurnal Pena Indonesia vol 2, No. 2, (Oktober 2016).

Nurul, Wahdah,،التدو الية:علاقتها باعلوم الأخرى وتطبيقتها بغير ها من المجالات، Jurnal Pendidikan Bahasa Arab dan Kebahasaan, vol 4, No. 1, 2016.

Parker, Frank. Linguistics for Non-Linguists. London: Taylor \& Francis Ltd, 1986.

Prasetia, Rita. Deiksis dalam Bahasa Arab. Tesis Program Pascasarjana FIB UI. Depok: Tidak Diterbitkan, 2004.

Soeparno. Dasar-Dasar Linguistik Umum. Yogyakarta: PT Tiara Wacana Yogya, 2002

Starkey, Paul. Modern Arabic Literature. Edinburg: Edinburg University Press Ltd, 2006.

Wijana, I Dewa. Dasar-dasar Pragmatik. Yogyakarta: Penerbit Andi, 1996.

Wiryotinoyo, Mujiyono. Pragmatik dalam Penelitian Penggunaan Bahasa. Bahasa dan Seni. Tahun 34, No 2, (2006).

Yule, George. The Study of Language (3rd ed.). New York: Cambridge University Press, 2006. 